\title{
Multi-targeted approach in the treatment of thyroid cancer
}

\author{
Scott N Pinchot \\ Rebecca S Sippel \\ Herbert Chen' \\ 'Endocrine Surgery Research \\ Laboratories, Department of Surgery, \\ University of Wisconsin \\ Madison, Wisconsin, USA
}

\begin{abstract}
While accounting for only $1 \%$ of solid organ malignancies ( $9 \%$ in women), thyroid carcinoma is the most common malignancy of the endocrine system. Although most patients have a favorable prognosis, over 1,500 people will die from thyroid carcinoma each year. The spectrum of disease types range from papillary thyroid cancer, which is a well-differentiated indolent tumor, to anaplastic carcinoma, a poorly differentiated fulminant cancer. With advances in diagnostic methods, surgical techniques, and clinical care of patients with thyroid carcinoma, the current management of thyroid cancer demands a multidisciplinary approach. The majority of patients with well-differentiated thyroid carcinoma of follicular cell origin are cured with adequate surgical management; however, some thyroid malignancies such as medullary thyroid carcinoma (MTC) or poorly differentiated thyroid carcinomas frequently metastasize, precluding patients from a curative resection. As such, novel palliative and therapeutic strategies are needed for this patient population. Here, we explore the current management of thyroid carcinoma, including surgical management of the primary tumor, lymph node disease, and locoregional recurrence. Likewise, we explore the application of current molecular techniques, reviewing nearly two decades of data that have begun to elucidate critical genetic pathways and therapeutic drug targets which may be important in specific thyroid tumor types.
\end{abstract}

Keywords: thyroid carcinoma; vascular endothelial growth factor receptor (VEGFR); epidermal growth factor receptor (EGFR); RET tyrosine kinase (RTK); glycogen synthase kinase-3 $\beta$ (GSK-3 $\beta)$

\section{Background}

Thyroid carcinoma is the most common cancer of the endocrine system (Hundahl et al 1998); in fact, approximately 33,550 patients are diagnosed with thyroid cancer annually in the United States, leading to an estimated 1,530 deaths per year (American Cancer Society 2007). While there are four main varieties of thyroid carcinoma, for purposes of clinical management of the patient, thyroid cancer is generally divided into three categories: well-differentiated thyroid cancer of follicular cell origin, medullary thyroid carcinoma (MTC), and undifferentiated or anaplastic cancer. Differentiated thyroid carcinomas are believed to arise from the follicular epithelial cells and account for nearly 94\% of all thyroid malignancies (Sherman 2003). Generally, differentiated thyroid cancers include papillary carcinoma (PTC), follicular carcinoma (FC), and Hürthle cell carcinoma (HCC). MTCs, neuroendocrine tumors involving the parafollicular $\mathrm{C}$ cells derived from the neural crest, comprise approximately $5 \%$ of thyroid cancers (Sherman 2003; Hanks 2004; Chen et al 1998b). Less common, poorly differentiated thyroid cancers tend to be more aggressive, metastasize earlier, and portend a generally worse prognosis. The most common of these, anaplastic thyroid carcinoma, is thought to develop from the dedifferentiation of the differentiated type (Sherman 2003).

In a national cancer database report on 53,856 cases of thyroid carcinoma treated in the US from 1985 to 1995 , Hundahl et al (1998) reported that 10-year overall relative 
survival rates for patients with papillary, follicular, Hürthle cell, and medullary carcinoma was $93 \%, 85 \%, 76 \%$, and $75 \%$, respectively. Patients with undifferentiated/anaplastic carcinoma (only $1.7 \%$ of the 53,856 cases) had a dismal prognosis, with only $14 \%$ surviving 10 years. Age at the time of diagnosis appears to be the most important independent prognostic variable, as the prognosis for differentiated thyroid carcinoma is better for patients younger than 40 years (Cady et al 1979; Sanders and Cady 1998; Dean and Hay 2000; Clark 1985); evidence suggests this age cutoff may extend to 50 years in women with no other negative prognostic factors. Likewise, size less than $4 \mathrm{~cm}$ and absence of distant metastasis at the time of initial treatment are important independent positive predictors of survival (Cady et al 1979; Sanders and Cady 1998; Dean and Hay 2000; Clark 1985).

Well-differentiated thyroid carcinoma is a unique, heterogeneous disease; unlike the majority of epithelial cancers, differentiated thyroid cancer patients do extremely well, with few having recurrences and even fewer dying from the disease. As a result, the best treatment modality for patients with well-differentiated thyroid carcinoma is a source of controversy. Tailoring treatment modalities to the patient's risk of recurrence or death is of paramount importance. Currently, several treatment modalities (ie, thyroidectomy, radioiodine ablation, and thyroid-stimulating hormone [TSH] suppressive therapy) are widely used in the treatment of thyroid carcinoma; however, recent data suggest that in spite of this multimodal approach to cancer care, relative survival rates have only minimally improved in the last several decades Sherman 2003; Colonna et al 2006). Of equal importance, chemotherapy and external beam radiation are minimally effective in the treatment of aggressive thyroid cancers (Haugen 1999), highlighting a need for the development of novel, effective therapies for thyroid carcinoma. Here, we review current multimodal therapies used in the treatment of thyroid carcinoma, and we discuss the recent efforts to identify novel chemotherapeutic targets which may be important in the treatment of this disease.

\section{Current therapeutic modalities}

With advances in diagnostic methods, surgical techniques, and clinical care of patients with thyroid carcinoma, the management of well-differentiated thyroid cancer demands a multidisciplinary approach. However, while multimodality therapy has been the cornerstone of treatment for most thyroid cancers, there are little prospective data to support this approach. Decisions about the best treatment for individual patients with thyroid carcinoma are often controversial and supported only by retrospective analyses. In an attempt to direct diagnosis and treatment decisions in patients with thyroid cancer, several guidelines for the current management of thyroid carcinoma have been offered (Udelsman and Chen 1999; Task Force TC 2001; Thyroid Carcinoma Task Force 2001; Kendall-Taylor 2003; Cooper et al 2006; Perros 2007; British Thyroid Association and Royal College of Physicians 2008).

\section{Primary surgical management}

Thyroidectomy is the preferred initial management of PTC, FC, MTC, HCC, and isolated metastases to the thyroid gland (Udelsman and Chen 1999; Chen et al 1999; Cheema et al 2006; Greenblatt et al 2007). In undifferentiated or anaplastic thyroid carcinoma, complete surgical resection is frequently not possible and there is no effective systemic therapy (Mazzaferri 2007); however, thyroidectomy may be utilized to make a definitive diagnosis or palliate symptoms of airway compromise (Udelsman and Chen 1999; Mazzaferri 2007; Lang and Lo 2007). Interestingly, though the outcomes for anaplastic thyroid carcinoma (ATC) are dismal, recent data suggest that complete surgical resection combined with radiation and chemotherapy (doxorubicin), in aggressive multimodal therapies, offers the best outcome in patients with ATC (Udelsman and Chen 1999; Sugino et al 2002; Lam et al 2000; Tennvall et al 1994).

The extent of thyroidectomy for well-differentiated thyroid carcinoma is controversial because no prospective randomized trial could be performed; however, it is clear that any surgery less than thyroid lobectomy has no role in the management of differentiated thyroid cancer. Based on several large retrospective reports, total thyroidectomy is the preferred initial surgical procedure for most patients with clinically significant (tumors $\geq 10 \mathrm{~mm}$ in diameter), well-differentiated thyroid cancer (Mazzaferri and Jhiang 1994; Chen and Udelsman 1998; Hay et al 1998; Katoh et al 1992; Taylor et al 1989). Recently, Bilimoria et al published the largest study on PTC to date (Bilimoria et al 2007); in a review of over 50,000 patients, bilobar resection was found to be associated with improved survival compared to thyroid lobectomy. This represents the only published report of a survival benefit to bilobar resection and has helped to answer the question over extent of surgery in patients with clinically significant PTC. The rationale for total thyroidectomy in the treatment of well-differentiated thyroid carcinoma is lent support by the following points: total thyroidectomy improves the effectiveness of radioactive iodine $\left({ }^{131} \mathrm{I}\right)$ ablation therapy, a significant factor shown to prolong survival and 
lower recurrence rates (Mazzaferri and Jhiang 1994; Chen and Udelsman 1998; DeGroot et al 1990; Krisnamurthy and Blahd 1977); the specificity of serum thyroglobulin concentrations as a tumor marker are highest with resection of as much thyroid tissue as is safely possible (Sherman 2003; Ozata et al 1994); total thyroidectomy reduces the recurrence rate in patients with well-differentiated thyroid cancer (DeGroot et al 1990; Mazzaferri and Young 1981; Mazzaferri et al 1977), specifically since $5 \%-10 \%$ of recurrences of PTC after lobectomy arise in the contralateral lobe (Sherman 2003; Silverberg et al 1970); and total thyroidectomy, in the hands of an experienced surgeon, has been shown to have equivalent morbidity and mortality rates as the unilateral (lobectomy) procedure (Chen et al 1998a; Clark 1982).

Most current guidelines for the management of welldifferentiated thyroid carcinoma suggest that patients with PTC more than $10 \mathrm{~mm}$ in diameter or with high-risk PTC or FTC (extrathyroidal extension of disease, bilateral or multicentric PTC, distant metastatic disease, or prior history of ionizing radiation to the neck) should undergo near-total or total thyroidectomy (Sherman 2003; British Thyroid Association and Royal College of Physicians 2008; Task Force TC 2001). It is generally accepted that thyroid lobectomy may be employed for patients with low-risk, occult PTC ( $\leq 10 \mathrm{~mm}$ in diameter), as the risk of death from a non-multicentric, $\leq 10 \mathrm{~mm}$ lesion is quite low (Udelsman and Chen 1999; Mazzaferri and Jhiang 1994). Conversely for FTC, although the absence of multicentric disease and small tumor size $(\leq 10 \mathrm{~mm}$ in diameter $)$ may argue against total thyroidectomy for management of the primary tumor, total thyroidectomy is typically recommended to allow for better outcomes with ${ }^{131}$ I ablation therapy (Sherman 2003; British Thyroid Association and Royal College of Physicians 2008).

As ultrasonography and fine-needle aspiration biopsy for thyroid lesions have recently increased in prevalence, the diagnosis of papillary thyroid microcarcinoma (PTMC) - thyroid carcinomas of less than $10 \mathrm{~mm}$ or less in maximum diameter (Hedinger et al 1988) - is becoming more common. The "ideal" therapeutic approach for patients with PTMC remains a subject of debate among endocrinologists and surgeons (Küçük et al 2007). While previous studies have shown that PTMC may account for nearly $30 \%$ of PTC cases, whether these microcarcinomas grow and become clinically apparent or life threatening for patients is unknown. In a recent observational trial of 162 patients, Ito et al (2003) showed that only $10.2 \%$ of low-risk PTMC enlarged by more than $10 \mathrm{~mm}$ during 5 years of follow-up and only $1.2 \%$ of patients developed lymph node metastases in the lateral compartments; more than $70 \%$ of tumors either did not change or decreased in size compared to the initial size at diagnosis, suggesting that PTMC may be observed as long as the tumor shows no progression. Ito et al further suggested that "if surgical treatment is performed for lowrisk [PTMC], prophylactic modified radical neck dissection is not necessary, and lobectomy (with isthmusectomy) and central node dissection is adequate if the tumor is located only in one lobe" (Ito and Miyauchi 2007).

\section{Management of lymph node disease}

While only $35 \%$ of patients with PTC have cervical or mediastinal lymph node metastases grossly detectable at the time of initial surgery (Sherman 2003), the presence of microscopic regional metastases to nodes is not uncommon. In fact, when prophylactic lymphadenectomy was performed on all patients with PTC in the early years of surgical management, up to $90 \%$ were found to have microscopic lymph node metastases (Udelsman and Chen 1999; Attie et al 1971; Frazell and Foote 1955). The presence of micrometastases in the cervical lymph nodes, however, has not been shown to affect survival (Young et al 1980; Hay et al 1993; Byar et al 1979; Grebe and Hay 1996). In a review of 1,019 patients with differentiated thyroid cancer treated between 1940 and 1990, Sanders et al noted no significant difference in 20-year adjusted survival rate among high-risk patients with involved nodes and without involved nodes (58.5\% versus $45.5 \%$, respectively) (Sanders and Cady 1998). Likewise, the 20-year adjusted survival rate was not significantly different in low-risk patients both with and without nodal involvement (94.6\% versus 96.5\%, respectively) (Sanders and Cady 1998). While a recent meta-analysis of several studies confirms no relationship between lymph node status at presentation and survival, several studies did show an increased risk of tumor recurrence (Sherman 2003; Grebe and Hay 1996). In a retrospective study, Simon et al (1996) showed $51 \%$ of patients with differentiated thyroid cancer who had a total thyroidectomy alone developed regional recurrence, compared with $18 \%$ who also had lymph node dissection.

Until recently, it has generally been accepted that lymph node status in PTC affects only local recurrence rates rather than survival. However, the topic has evolved considerably in the last several years, as data from a large population-based study have demonstrated significantly higher mortality rates for differentiated thyroid cancer with nodal involvement (Lundgren et al 2006). When lymph node metastases are clinically evident on physical examination or routine cervical 
ultrasound, it is generally agreed upon in most centers that surgical lymphadenectomy (LND) is the best form of treatment. In fact, many centers, including our own institution, have advocated ipsilateral modified radical neck dissection (MRND) as described by Bocca et al $(1980,1984)$ for clinically evident nodal involvement in the lateral neck to reduce the frequency of regional recurrence. Likewise, central neck dissection is warranted for PTC with clinically evident or pathologically involved nodes in the central compartment of the neck (also known as level IV), the region most frequently involved with skip metastases (Machens et al 2004; Qubain et al 2002).

However, controversy exists regarding the role of routine or prophylactic LND in PTC cases where nodal disease is not clinically detected (Sywak et al 2006). In a retrospective cohort study of nearly 450 patients, Sywak et al have demonstrated that, in PTC, the addition of routine central lymph node dissection (CLND) results in lower postablation thyroglobulin levels and potentially reduces recurrent or persistent disease and avoids reoperative surgery. Similarly, through an evidence-based meta-analysis of relevant literature, White et al (2007) provide levels IV and V data suggesting that systematic compartment-oriented CLND may decrease recurrence of PTC and likely improves disease-specific survival (grade $\mathrm{C}$ recommendation). Additionally, limited level III data are provided suggesting a survival benefit with the addition of prophylactic dissection to thyroidectomy (grade $\mathrm{C}$ recommendation). While the debate will undoubtedly continue, at our institution we do not routinely perform routine or prophylactic MRND or CLND in the absence of clinically evident nodal disease, as there are no convincing level I or II data demonstrating the benefit of prophylactic nodal dissection in these patients with PTC (Udelsman and Chen 1999).

Lymph node involvement with FTC is rare; in fact, nodal disease is present in less than $13 \%$ of patients in most comprehensive reviews (Emerick et al 1993). Rather, follicular carcinomas have a predilection for hematogenous metastasis, commonly invading blood vessels en route to bone and lung. Importantly, the oxyphilic variant of follicular thyroid carcinoma (HCC) behaves in a more aggressive fashion than well-differentiated FTC and, if malignant, often shows early nodal spread (Sherman 2003). Likewise, due to its relatively low avidity for radioiodine, HCC is essentially a surgical disease. Therefore, nodal disease from all differentiated thyroid carcinomas of follicular cell origin (PTC, FTC, and HCC) should be treated with aggressive surgical resection of clinically evident nodal disease; that is, CLND is advocated for clinically evident or pathologically proven nodal disease in the central neck while ipsilateral MRND is advocated for obvious disease in the lateral neck.

Unlike well-differentiated follicular thyroid carcinomas, MTC is more likely to present with metastatic cervical adenopathy (50\%) at the time of initial presentation (Sherman 2003); early lymphatic spread to the perithyroidal and pretracheal lymph nodes is not uncommon. Similarly, more extensive lymphatic spread commonly involves the lateral compartments, including the jugular and supraclavicular nodes. In a recent report by Machens et al tumor multifocality was found to be an independent risk factor of lymph node metastasis on top of primary tumor size (Machens et al 2007). The hereditary form of MTC - those carcinomas showing an autosomal dominant pattern of transmission and arising as part of multiple endocrine neoplasia (MEN) syndrome types 2A or 2B or familial MTC (FMTC) - is characterized by the early onset of multifocal and bilateral disease (Scollo et al 2003). The sporadic form, accounting for nearly $70 \%$ of MTC cases, has been shown to have palpable cervical adenopathy in 30\%-60\% of cases (Chong et al 1975; Rougier et al 1983; Saad et al 1984). Lymph node involvement is present in 10\%-30\% of tumors smaller than $10 \mathrm{~mm}$ (Beressi et al 1998; Gimm et al 1999) and is more frequent in patients with larger tumors (Machens et al 2007). For these reasons, total thyroidectomy and bilateral CLND is recommended for all MTC patients; moreover, ipsilateral MRND is advocated in cases of sporadic MTC with clinically evident cervical adenopathy, tumors larger than $10 \mathrm{~mm}$ in diameter, and involvement of the central neck compartment (Udelsman and Chen 1999; Scollo et al 2003; Shaha 1998; Kebebew and Clark 2000; Mazzaferri 1999).

\section{Role of ${ }^{|3|} \mid$ adjuvant therapy}

Near-total and total thyroidectomy followed by ${ }^{131} \mathrm{I}$ ablation confers a distinct outcome advantage for PTC and FTC. There are multiple reasons for the use of adjuvant radioiodine ablation of residual thyroid tissue following thyroidectomy: (1) to destroy residual microscopic foci of disease; (2) to improve monitoring of recurrent or metastatic disease with ${ }^{131}$ I scanning by eliminating uptake by normal thyroid tissue and improving the specificity of the scan; and (3) to enhance the value of serum thyroglobulin measurements as a serum marker of recurrent disease (Sherman 2003). Significant retrospective data from multiple large studies suggest that ${ }^{131} \mathrm{I}$ ablation reduces long-term disease specific mortality in those patients whose primary tumors are $\geq 10 \mathrm{~mm}$ in diameter, are multicentric, or have capsular or soft-tissue invasion at 
presentation (Sherman 2003; Mazzaferri and Jhiang 1994; Taylor et al 1989; DeGroot et al 1990; Krisnamurthy and Blahd 1977; Wong et al 1990). Radioiodine ablation has been shown to be ineffective in patients with MTC and is only minimally effective in HCC; hence, it is not commonly used in these patients. Significant complications of ${ }^{131}$ I ablation include sialoadenitis, parotid gland pain, altered taste sensation, and dysphagia; these side effects are thought to result from radiation damage to the salivary glands, organs which have been shown to concentrate $\mathrm{Na}^{131}$ I uptake via a carrier-mediated mechanism (Solans et al 2001). Though much less common, symptoms of lacrimal gland dysfunction (sicca syndrome), gastrointestinal symptoms, bone marrow suppression, and infertility have been reported (Solans et al 2001; Sawka et al 2008a). Interestingly, though abnormalities in testicular function are common within several months of a single therapeutic dose of radioactive iodine (RAI) $(<150 \mathrm{mCi})$, these biochemical abnormalities have been shown to resolve within 18 months (Sawka et al 2008a). In women treated with RAI for thyroid carcinoma, few adverse effects of RAI treatment related to gonadal function, fertility, or pregnancy are noted beyond 12 months, with the exception of a possible slightly earlier age of menopause (Sawka et al 2008b).

\section{Thyroid-stimulating hormone suppressive therapy}

Experimental investigations have demonstrated that differentiated thyroid cancer cells have membrane-bound thyroid-stimulating hormone (TSH) receptors and that the growth regulation of differentiated thyroid cancer depends upon TSH (Shiba et al 1989). Furthermore, TSH suppression by administration of thyroid hormone (L-thyroxine) has been shown to lower the recurrence rates FTC and PTC (Emerick et al 1993; Young et al 1980; Clark 1981; Mazzaferri 1987; Mazzaferri and Jhiang 1994) and improves survival after thyroidectomy (Schneider et al 1978; Fogelfeld et al 1998). Likewise, Clark and Gerend (1985) have shown that most HCCs have thyrotropin receptors; therefore, all patients with HCC are typically given postoperative thyrotropin suppression therapy (Yutan and Clark 2001). Currently, the appropriate degree of TSH suppression remains controversial. In a study of 141 patients who underwent hormone therapy following thyroidectomy, Pujol et al showed that relapse-free survival (RFS) was longer in patients with a greater degree of TSH suppression (all TSH values $\leq 0.05 \mathrm{mU} / \mathrm{L}$ ); furthermore, multivariate analysis that included TSH levels, age, sex, histology, and tumor node metastases stage showed that TSH levels predicted RFS independently of other variables (Pujol et al 1996). At our institution, we attempt to maintain TSH levels lower than $0.1 \mathrm{mU} / \mathrm{L}$ and aim for undetectable levels. Historically, adverse clinical outcomes attributed to prolonged L-thyroxine suppressive therapy have included bone and cardiac disease (Burmeister 1994; Paloyan et al 1998; Bauer 1997); however, recent data suggest that patients with well-differentiated thyroid carcinoma are not at increased risk of developing low bone mass nor have a higher prevalence of vertebral fracture when treated with relatively low doses of L-thyroxine (Heijckmann et al 2005).

\section{Molecular pathogenesis and cytogenetics}

Although most thyroid carcinomas are relatively indolent, there have been no significant improvements in survival over the last two decades. In fact, the trend in US cancer mortality with associated annual percentage change (APC) for cancer of the thyroid is disturbing; while an average $3 \%$ decrease in mortality from thyroid cancer was seen in males and females from 1975-1985, such a decrease has been absent in either gender since 1985 (NCI 2008). More intriguing, Surveillance Epidemiology and End Results (SEER) data indicate a 6.2\% increased incidence of thyroid cancer during the same two decades (NCI 2008). Clearly, insight into the molecular pathogenesis of HCC, MTC, ATC, and other aggressive forms of thyroid cancer may lead to the development of more targeted therapies in the future.

Fortunately, the molecular basis of well-differentiated thyroid carcinoma, MTC, and anaplastic thyroid cancer is currently under investigation. With the application of current molecular techniques, nearly two decades of research have begun to elucidate critical genetic pathways involved in the development of specific thyroid tumor types. In particular, chromosomal inversions or translocations causing mutations in the RET proto-oncogene may play an important role in approximately $40 \%$ of patients with PTC (Vidal et al 2005; Carlomagno et al 2002). Likewise, mutations that activate RET activity can lead to several hereditary cancer syndromes, including MEN types 2A and 2B and FMTC. Some studies suggest that differentiated thyroid carcinoma cell invasion is regulated through epidermal growth factor receptordependent (EGFR) activation of matrix metalloproteinases (Yeh et al 2006). Anaplastic thyroid carcinoma is postulated to develop secondary to dedifferentiation from a more differentiated tumor and has been associated with the loss of the p53 tumor suppressor protein (Sherman 2003; Moretti et al 1997). Many of these findings have paved the way for the 
development of phase II/III clinical trials, several of which may be found in Table 1. Fortunately, the importance of these genetic pathways, as well as a myriad of others, continue to be described today.

\section{The RET receptor tyrosine kinase (RTK)}

The RET gene encodes a $120-\mathrm{kDa}$ transmembrane tyrosine kinase that functions as a receptor for the glial-derived neurotrophic factor (GDNF) family of growth factors (Manie et al 2001). Mutations in the RET proto-oncogene have been implicated in patients with hereditary MTC associated with MEN types 2A and 2B and familial MTC (FMTC). Likewise, nearly $40 \%$ of patients with PTC have rearrangements of the RET gene that join the promoter and $\mathrm{NH}_{2}$-terminal domains of unrelated genes to the $\mathrm{COOH}$-terminal fragment of RET (Vidal et al 2005). The cumulative result of the point

Table I National Cancer Institute/US National Institutes of Health list of clinical trials now accepting participants

\begin{tabular}{|c|c|c|c|c|c|}
\hline Clinical trial title & Phase & Type & Status & Age & Sponsor \\
\hline $\begin{array}{l}\text { I. Effect of Lithium Carbonate on Low-Dose Radioiodine } \\
\text { Therapy in Early Thyroid Cancer }\end{array}$ & II & Treatment & Active & 16 and over & NIDDK \\
\hline $\begin{array}{l}\text { 2. Safety and Efficacy Study of In- I I I Pentetreotide to } \\
\text { Treat Neuroendocrine Tumors }\end{array}$ & III & Treatment & Active & 18 and over & Other \\
\hline $\begin{array}{l}\text { 3. Clinical and Translational Study of MK-0646 in Patients } \\
\text { With Metastatic Neuroendocrine Tumors (NET) }\end{array}$ & II & Treatment & Active & 18 and over & Other \\
\hline $\begin{array}{l}\text { 4. Avastin (Bevacizumab) and RAD00I (Everolimus) in } \\
\text { Advanced Low or Intermediate Grade Neuroendocrine } \\
\text { Carcinoma }\end{array}$ & II & Treatment & Active & 18 and over & Other \\
\hline $\begin{array}{l}\text { 5. An Initial Study of Lithium in Patients With Medullary } \\
\text { Thyroid Cancer }\end{array}$ & NS & Treatment & Active & 18 and over & Other \\
\hline 6. Thyroid Cancer and Sunitinib & II & Treatment & Active & 18 and over & Other \\
\hline $\begin{array}{l}\text { 7. Phase } 2 \text { Study Of AG-0I3736 In Patients With } \\
\text { Doxorubicin-Refractory Or Intolerant Thyroid Cancer }\end{array}$ & II & Treatment & Active & 18 and over & Pharmaceutical/Industry \\
\hline $\begin{array}{l}\text { 8. Efficacy and Safety of Lanreotide Autogel in } \\
\text { Tumour Stabilization of Patients With Progressive } \\
\text { Neuroendocrine Tumours }\end{array}$ & II & Treatment & Active & 18 and over & Pharmaceutical/Industry \\
\hline $\begin{array}{l}\text { 9. Phase II Two-Step Radioimmunotherapy Clinical Study } \\
\text { in Medullary Thyroid Carcinoma }\end{array}$ & II & Treatment & Active & 18 to 75 & Other \\
\hline $\begin{array}{l}\text { 10. A Phase I Study of BMS-6905 I4 in Patients With } \\
\text { Advanced or Metastatic Solid Tumors }\end{array}$ & 1 & Treatment & Active & 18 and over & Pharmaceutical/Industry \\
\hline $\begin{array}{l}\text { II. Sorafenib in Treating Patients With Advanced } \\
\text { Anaplastic Thyroid Cancer }\end{array}$ & II & Treatment & Active & 18 and over & $\mathrm{NCl}$ \\
\hline 12. Lithium for Low-Grade Neuroendocrine Tumors & II & Treatment & Active & 18 and over & $\mathrm{NCl}$, Other \\
\hline $\begin{array}{l}\text { 13. The Safety and Efficacy of CPTK787/ZK222584 in } \\
\text { Patients With Metastatic Neuroendocrine Tumors }\end{array}$ & II & Treatment & Active & 18 and over & Other \\
\hline $\begin{array}{l}\text { 14. A Phase I/2 Dose Finding Study of an Experimental } \\
\text { New Drug CS70I7, an Oral PPAR } \gamma \text { Agonist Taken by } \\
\text { Mouth Twice Daily in Combination With Paclitaxel } \\
\text { Chemotherapy Administered Every Three Weeks by } \\
\text { Venous Infusion by Patients With Anaplastic Thyroid } \\
\text { Cancer }\end{array}$ & I, II & Treatment & Active & 18 and over & Pharmaceutical/Industry \\
\hline $\begin{array}{l}\text { 15. Efficacy and Safety of Zactima }{ }^{\mathrm{Tm}} \text { in Patients With Meta- } \\
\text { static Papillary or Follicular Thyroid Cancer }\end{array}$ & II & Treatment & Active & 18 and over & Pharmaceutical/Industry \\
\hline $\begin{array}{l}\text { 16. Boronophenylalanine-Fructose Complex (BPA-F) and/ } \\
\text { or Sodium Borocaptate (BSH) Followed By Surgery in } \\
\text { Treating Patients With Thyroid Cancer, Head and Neck } \\
\text { Cancer, or Liver Metastases }\end{array}$ & I & Treatment & Active & 18 and over & Other \\
\hline $\begin{array}{l}\text { 17. Irinotecan in Treating Patients With Metastatic or } \\
\text { Inoperable Thyroid Cancer }\end{array}$ & II & Treatment & Active & 18 and over & $\mathrm{NCl}$ \\
\hline $\begin{array}{l}\text { 18. I7-AAG in Treating Patients With Inoperable } \\
\text { Locoregionally Advanced or Metastatic Thyroid Cancer }\end{array}$ & II & Treatment & Active & 18 and over & $\mathrm{NCl}$ \\
\hline
\end{tabular}

(Continued) 


\begin{tabular}{|c|c|c|c|c|c|}
\hline Clinical trial title & Phase & Type & Status & Age & Sponsor \\
\hline $\begin{array}{l}\text { 19. Pazopanib in Treating Patients With Advanced Thyroid } \\
\text { Cancer }\end{array}$ & II & $\begin{array}{l}\text { Biomarker/ } \\
\text { Laboratory } \\
\text { Analysis, } \\
\text { Treatment }\end{array}$ & Active & 18 and over & $\mathrm{NCl}$ \\
\hline $\begin{array}{l}\text { 20. AZD6244 in Treating Patients With Papillary Thyroid } \\
\text { Cancer That Did Not Respond to Radioactive lodine }\end{array}$ & II & $\begin{array}{l}\text { Biomarker/ } \\
\text { Laboratory } \\
\text { Analysis, } \\
\text { Treatment }\end{array}$ & Active & 18 and over & $\mathrm{NCl}$ \\
\hline $\begin{array}{l}\text { 21. FR90I228 in Treating Patients With Recurrent and/or } \\
\text { Metastatic Thyroid Cancer That Has Not Responded } \\
\text { to Radioactive lodine }\end{array}$ & II & Treatment & Active & 18 and over & $\mathrm{NCl}$ \\
\hline $\begin{array}{l}\text { 22. FR90 I228 in Treating Patients With Refractory Thyroid } \\
\text { Cancer or Other Advanced Cancer }\end{array}$ & I & Treatment & Active & 18 and over & $\mathrm{NCl}$ \\
\hline $\begin{array}{l}\text { 23. Vandetanib in Treating Young Patients With Medullary } \\
\text { Thyroid Cancer }\end{array}$ & II & $\begin{array}{l}\text { Biomarker/ } \\
\text { Laboratory } \\
\text { Analysis, } \\
\text { Treatment }\end{array}$ & Active & 5 to 18 & $\mathrm{NCl}$ \\
\hline $\begin{array}{l}\text { 24. Sorafenib in Treating Patients With Metastatic, Locally } \\
\text { Advanced, or Recurrent Medullary Thyroid Cancer }\end{array}$ & II & $\begin{array}{l}\text { Biomarker/ } \\
\text { Laboratory } \\
\text { Analysis, } \\
\text { Treatment }\end{array}$ & Active & 18 and over & $\mathrm{NCl}$ \\
\hline $\begin{array}{l}\text { 25. Study of Combretastatin and Paclitaxel/Carboplatin } \\
\text { in the Treatment of Anaplastic Thyroid Cancer }\end{array}$ & III & Treatment & Active & 18 and over & Pharmaceutical/Industry \\
\hline $\begin{array}{l}\text { 26. Efficacy Study of Sorafenib and Cyclophosphamide } \\
\text { to Treat Neuroendocrine Tumors }\end{array}$ & II & Treatment & Active & 18 and over & Other \\
\hline $\begin{array}{l}\text { 27. Sunitinib in Treating Patients With Thyroid Cancer } \\
\text { That Did Not Respond to lodine I I } 3 \text { I and Cannot Be } \\
\text { Removed by Surgery }\end{array}$ & II & Treatment & Active & 18 and over & $\mathrm{NCl}$ \\
\hline $\begin{array}{l}\text { 28. Rosiglitazone in Treating Patients With Locoregionally } \\
\text { Extensive or Metastatic Thyroid Cancer }\end{array}$ & II & Treatment & Active & 18 and over & $\begin{array}{l}\text { Pharmaceutical/Industry, } \\
\mathrm{NCl}\end{array}$ \\
\hline $\begin{array}{l}\text { 29. Lenalidomide in Treating Patients With Metastatic Thyroid } \\
\text { Cancer That Has Not Responded to Radioactive lodine and } \\
\text { Cannot Be Removed By Surgery }\end{array}$ & II & $\begin{array}{l}\text { Biomarker/ } \\
\text { Laboratory } \\
\text { Analysis, } \\
\text { Treatment }\end{array}$ & Active & 18 and over & $\begin{array}{l}\text { Pharmaceutical/Industry, } \\
\text { Other }\end{array}$ \\
\hline $\begin{array}{l}\text { 30. Trial Evaluating Gleevec in Patients With Anaplastic Thyroid } \\
\text { Carcinoma }\end{array}$ & II & Treatment & Active & 18 and over & Other \\
\hline $\begin{array}{l}\text { 31. Sorafenib in Treating Patients With Metastatic or } \\
\text { Unresectable Resistant Thyroid Cancer }\end{array}$ & II & $\begin{array}{l}\text { Biomarker/ } \\
\text { Laboratory } \\
\text { Analysis, } \\
\text { Treatment }\end{array}$ & Active & NS & $\mathrm{NCl}$ \\
\hline $\begin{array}{l}\text { 32. Valproic Acid (Depakote ER) in Patients With Advanced } \\
\text { Thyroid Cancer }\end{array}$ & II & Treatment & Active & 18 and over & $\mathrm{NCl}$, Other \\
\hline
\end{tabular}

Abbreviations: NS, not specified; NCl, national cancer institute; NIDDK, national institute of diabetes and digestive and kidney diseases.

mutations associated with MEN 2A and 2B and FMTC and the chromosomal rearrangements associated with PTC is activation of the RET receptor tyrosine kinase (RTK).

While MTC tends to be a slow-growing tumor primarily treated with surgical resection, it also frequently metastasizes to the liver and regional lymph nodes, precluding patients from a curative resection. Clearly, there is a great need for novel therapeutic and palliative strategies to treat these patients with metastatic MTC. RTK inhibitors are likely to be beneficial for patients with hereditary MTC, where currently there are no effective chemotherapy or radiotherapy options.

ZD6474 (vandetanib) is a low-molecular-weight tyrosine kinase inhibitor that has demonstrated potent and selective inhibition of RTK in vitro (Carlomagno et al 2002; Wedge et al 2002). In additional pre-clinical studies, 
Carlomagno et al (2005) have shown that ZD6474 blocks in vivo phosphorylation and signaling of the RET/PTC3 and RET/MEN2B oncoproteins, inhibits the proliferative autonomy of RET/PTC3-transformed cells, and prevents the growth of two human PTC cell lines that carry spontaneous RET/PTC1 rearrangements. Based on phase I studies, ZD6474 was generally well tolerated at doses $\leq 300 \mathrm{mg} /$ day and adverse events were generally mild and limited by dose adjustment. The most common monotherapy-related adverse outcomes included diarrhea, asymptomatic QTc prolongation, and a skin rash (Holden et al 2005; Tamura et al 2006). Currently, promising data in patients with MTC have led to ZD6474 being assigned orphan drug designation by the US Food and Drug Administration. These data are based on studies in which ZD6474 has demonstrated clinical activity in a single-arm Phase II study in 30 patients with metastatic hereditary MTC (Wells et al 2007). Concomitantly, an international, randomized, placebo-controlled phase II study of ZD6474 monotherapy in metastatic MTC is currently recruiting patients.

In addition to ZD6474, several other novel RTK inhibitors, sorafenib and sunitinib, for example, are under investigation for treatment of RET-dependent thyroid carcinomas. Utilizing an orthotopic anaplastic thyroid carcinoma xenograft model in nude mice, Kim et al have shown that sorafenib, a multikinase inhibitor of RTK, VEGFR, and BRAF kinase, inhibits proliferation of ATC cell lines and inhibits tumor angiogenesis via induction of endothelial apoptosis (Kim et al 2007). Similarly, the orally administered multitarget tyrosine kinase inhibitor, SU11248 (sunitinib), has been shown to be a novel potent inhibitor of thyroid oncogenic RET/papillary thyroid cancer kinases (Kim et al 2006).

\section{EGFR as a therapeutic target in human thyroid carcinoma}

Epidermal growth factor (EGF) is a 6-kDa polypeptide which has been shown to stimulate the proliferation of normal and malignant thyroid cells and inhibit cellular differentiation Hoelting et al 1994). Overexpression of the EGF receptor (EGFR), a transmembrane 170-kDa glycoprotein tyrosine kinase, is frequently detected in thyroid carcinomas, and though controversial (Mitsiades et al 2006), this pathway has been proposed to be important for thyroid carcinoma proliferation and metastasis. Recent studies with gefitinib and erlotinib, well-known EGFR kinase inhibitors, have resulted in objective responses in patients with non-small cell lung cancers (NSCLC), tumors in which EGFR is also frequently overexpressed. This has led some to believe that novel therapeutic compounds targeting the EGFR pathway may have future palliative and therapeutic potential in patients with refractory or metastatic thyroid carcinomas. In fact, the aforementioned compound ZD6474 is, in addition to its role in RTK inhibition, a potent and selective inhibitor of vascular endothelial growth factor receptor (VEGFR) and EGFR. As above, this compound is currently in phase II clinical trials to measure its efficacy and clinical impact in patients with hereditary MTC.

Interestingly, many of the novel RTK inhibitors, ZD6474, sorafenib, and sunitinib, for example, appear to non-specifically inhibit multiple signaling pathways critical in thyroid carcinogenesis, suggesting a potential synergistic effect to these novel drugs; however, the question of whether this lack of specificity will be advantageous or disadvantageous in the long run for patients remains unanswered.

More recently, studies have demonstrated that differentiated thyroid cancer cell invasion in vivo is regulated through EGFR-dependent activation of matrix metalloproteinase (MMP)-2/gelatinase A (Yeh et al 2006). Undoubtedly, the role of MMP inhibitors as effective anti-tumor agents for the treatment of aggressive thyroid carcinomas is intriguing.

\section{BRAF mutations in PTC}

Kimura et al studied 124 snap frozen tumor samples, including 78 papillary carcinomas, using DNA isolation and single-strand conformational polymorphism (SSCP) analyses (Kimura et al 2003). Overall, 28 of 124 cancers demonstrated mutations in exon 15 of the B-type Raf kinase (BRAF) gene; all had the same thymine-to-adenine transversion at nucleotide 1796 , resulting in a valine-to-glutamate substitution at residue 600 (currently designated as V600E). More importantly, all of the $B R A F^{V 600 E}$ mutations were in papillary carcinomas (Kimura et al 2003). By contrast, all 46 of the follicular neoplasms were wild-type. Since this initial report, Xing has shown that the BRAF activating mutation is the most common genetic alteration in thyroid cancer (Xing 2005), occurring in $18 \%$ to $87 \%$ of thyroid cancers (Trovisco et al 2006); importantly, the $B R A F^{V 600 E}$ mutation occurs in nearly $45 \%$ of sporadic cases of PTC (Xing 2005) and 24\% of cases of anaplastic carcinoma (Salvatore et al 2006). Recently, Kebebew and colleagues sought to determine the association of $B R A F$ mutations with indicators of poor prognosis for PTC and patient outcome in an attempt to determine whether $B R A F^{V 600 E}$ is associated with an aggressive tumor phenotype (Kebebew et al 2007). In patients with conventional PTC, patients with the $B R A F^{V 600 E}$ mutation were associated with a more aggressive tumor phenotype and were characterized by older age at the time of 
initial presentation, the presence of lymph node and/or distant metastases, higher TNM stage, and recurrent or persistent disease with a median follow-up of 6 years (Kebebew et al 2007). Genetic analysis for BRAF mutations in patients with PTC may enable better prediction of those tumors associated with a poor prognosis and may be useful in selecting initial therapeutic modalities in these patients.

\section{The raf-I/mitogen-regulated extracellular kinase (MEK)/extracellular regulated kinase (ERK) pathway in MTC}

The raf-1/MEK/ERK pathway has long been recognized for its role in cancer biology. Although activation of this signaling pathway is commonly considered to be growth promoting in several cancers, in certain cell-specific subtypes, raf-1 activation results in growth suppression (Kunnimalaiyaan et al 2007b). Specifically, activation of the raf-1 signaling pathway in MTC has been shown to lead to significant morphologic differentiation and growth reduction both in vitro and in a mouse xenograft TT model in vivo (Ravi et al 1998, 1999; Park et al 2003; Vaccaro et al 2006). Similarly, we have shown that raf-1 activation results in a reduction of the neuroendocrine tumor markers achaete-scute complex-like 1 (ASCL1), chromogranin $\mathrm{A}(\mathrm{CgA})$, and calcitonin in vitro (Park et al 2003; Kunnimalaiyaan and Chen 2006; Chen et al 2005; Sippel et al 2003).

Until recently, the mechanism by which raf-1 pathway activation inhibits MTC cell growth was unclear; in fact, conflicting observations had been reported regarding the regulation of ERK1/2 in MTC cancer cells. Recent studies into the role of GSK-3 $\beta$ and its downstream relationship to Raf-1 have begun to elucidate the mechanisms responsible for growth inhibition in MTC cells.

\section{Inactivation of glycogen synthase kinase- $3 \beta$ (GSK-3 $\beta$ ) in MTC}

GSK-3 $\beta$ is a multifunctional serine/threonine protein kinase that plays an important role in cellular metabolism, cell fate determination, proliferation, and survival (Hardt and Sadoshima 2002; Harwood et al 1995). The activity of this kinase is inhibited by phosphorylation of a single serine residue $\left(\mathrm{Ser}^{9}\right)$. Thus, unlike other kinases, GSK-3 $\beta$ is highly active when non-phosphorylated (in unstimulated cells), and becomes inactivated (phosphorylated) in response to signaling cascades, including the raf-1/MEK/ERK pathway (Cohen and Frame 2001). At our institution, Kunnimalaiyaan et al (2007b) found that raf-1 activation in human MTC cells (TT cells) results in phosphorylation of GSK-3 $\beta$ (Kunnimalaiyaan et al 2007b). Furthermore, inactivation of GSK-3 $\beta$ by phosphorylation results in MTC growth inhibition both in vitro and in vivo. Inactivation of GSK-3 $\beta$ in TT cells with well known GSK-3 $\beta$ inhibitors such as lithium chloride ( $\mathrm{LiCl})$ and SB216763 is associated with a significant decrease in neuroendocrine markers such as human-achaete-scute complex-like 1 (ASCL1) and chromogranin $\mathrm{A}(\mathrm{CgA})$. $\mathrm{LiCl}$ has been utilized clinically for more than fifty years as an adjunctive psychiatric medication for the treatment of bipolar disorder and has shown only minimal adverse side effects. As such, the efficacy of $\mathrm{LiCl}$ therapy in patients with MTC is currently being investigated at our institution in phase II clinical trials.

\section{Overexpression of the Notch I intracellular domain in MTC}

Notch1 is a multifunctional transmembrane receptor that regulates cellular differentiation, proliferation, and survival (Kadesh 2004; Maillard and Pear 2003; Yoon and Gaiano 2005). Binding of any one of the Notch ligands (Delta1 (DLL1) or Jagged1 (JAG-1), for example) promotes a sequence of proteolytic cleavages resulting in the activated Notch intracellular domain (NICD). The active NICD then translocates to the nucleus and binds with the DNA-binding protein complex CSL $(\mathrm{CBF} 1, \mathrm{Su}(\mathrm{H})$, and LAG-1), resulting in the transcriptional activation of target genes such as hairy enhancer of split-1 (HES-1) (Kunnimalaiyaan et al 2007a). In human cancer cells, Notch1 has a dual role as either a tumor suppressor or an oncogene. It has been shown that Notch1 is upregulated in many types of cancer, including pancreatic cancer, colon cancer, non-small cell cancer, cervical cancer, renal cell carcinoma, and several lymphomas. It has been suggested that expression of Notch1 signaling prevents cellular differentiation and inhibits apoptosis in certain cancers. Conversely, Notch1 signaling is very minimal or absent in prostate cancer and NETs such as small-cell lung cancer (SCLC), pancreatic carcinoid, and MTC (Kunnimalaiyaan and Chen 2007). These apparent but paradoxical functions clearly indicate that the role of Notch signaling is dependent on its cellular context.

Using a doxycycline-inducible NICD in MTC cells (TT cells), we have recently shown that overexpression of Notch1 in MTC cells - Notch1 signaling is normally absent in MTC cells - results in a dose-dependent reduction in NE tumor markers and growth (Kunnimalaiyaan et al 2006, 2007a; Kunnimalaiyaan and Chen 2007). These findings indicate that identification of compounds capable of pharmacologically activating the Notch1 signaling may have a therapeutic role in treating $\mathrm{NE}$ diseases caused by aberrant expression of ASCL1 and other hormones. In fact, our laboratory has recently shown the histone deacetylase (HDAC) 
inhibitors valproic acid (VPA) and suberoyl bis-hydroxamic acid (SBHA) to be strong Notch1 activators in NE tumors, including MTC. Moreover, we have shown these compounds to limit growth and reduce neuroendocrine markers both in vitro and in vivo. The efficacy of these HDAC inhibitors as part of a comprehensive therapy in patients with MTC is currently being investigated at our institution in ongoing phase II clinical trials.

\section{Mutation of the p53 tumor suppressor gene}

The tumor suppressor gene, p53, plays a critical role in cell cycle control, DNA repair, and synthesis, apoptosis, and many other cellular processes. Though it is believed that nearly $50 \%$ of all human malignancies are due to inactivating mutations of the p53 tumor suppressor gene, the significance of the p53 gene in thyroid carcinogenesis is less clear (Malaguarnera et al 2007). In a review of the International Agency for Research on Cancer (IARC) TP53 tumor suppressor database, the largest comprehensive database of its kind in existence, Olivier et al showed inactivating mutations of the p53 gene have been found in only $10 \%$ of thyroid carcinomas and mainly in poorly differentiated and aggressive histotypes (Olivier et al 2002). Similarly, in a cohort of nearly 100 patients, Saltman et al clearly demonstrated the presence of aberrant p53 expression in more aggressive phenotypes of thyroid carcinoma; the study demonstrated a gradual increase in p53 immunopositivity rate along the spectrum of thyroid carcinoma progression with a statistically significant difference between well-differentiated PTC and anaplastic phenotypes ( $0 \%$ vs $31.8 \%$, respectively; $\mathrm{p}<0.001$ ) (Saltman et al 2006). Clearly, studies elucidating the role of inactivating mechanisms in the early stages of thyroid cancer are needed to help facilitate a better understanding of the complex network of p53 family member isoforms and their role in thyroid carcinogenesis.

\section{Conclusion}

While constituting only $1 \%$ of solid organ malignancies ( $9 \%$ in women), thyroid carcinoma is the most common malignancy of the endocrine system. The majority of patients with well-differentiated thyroid carcinoma are cured with adequate surgical management; however, some thyroid malignancies such as MTC or poorly differentiated thyroid carcinomas frequently metastasize, precluding patients from a curative resection. As such, novel palliative and therapeutic strategies are needed for this patient population. This review is a summary of our standard treatment strategies for PTC,
MTC, HCC, follicular cancers, and anaplastic carcinoma of the thyroid. In addition, we hope to shed some light on the molecular pathogenesis and cytogenetics of these cancers by providing information on the myriad cell signaling pathways currently under investigation. We acknowledge that while not entirely inclusive of all ongoing research, the above mentioned pathways appear significant in the tumorigenesis of thyroid carcinoma.

\section{Disclosures}

None of the authors has any conflicts of interest to disclose.

\section{References}

American Cancer Society. 2007. Cancer Facts and Figures 2007. Accessed 8 January 2008. URL: http://www.cancer.org/downloads/STT/ CAFF2007PWSecured.pdf.

Attie JN, Khafif RA, Steckler RM. 1971. Elective neck dissection in papillary carcinoma of the thyroid. Surgery, 111:604-9.

Bauer D. 1997. Low thyrotropin levels are not associated with bone loss in older women:A prospective study. J Clin Endocrinol Metab, 82:2931-5.

Beressi N, Campos JM, Beressi JP, et al. 1998. Sporadic medullary microcarcinoma of the thyroid:a retrospective analysis of eighty cases. Thyroid, 8:1039-44.

Bilimoria KY, Bentrem DJ, Ko CY, et al. 2007. Extent of surgery affects survival for papillary thyroid cancer. Ann Surg, 246:375-81.

Bocca E, Pignataro O, Sasaki CT. 1980. Functional neck dissection: a description of operative technique. Arch Otolaryngol, 106:524-7.

Bocca E, Pignataro O, Oldini C, et al. 1984. Functional neck dissection: an evaluation and review of 843 cases. Laryngoscope, 94:942-5.

Burmeister LA. 1994. Thyroid hormone in the treatment of thyroid cancer. Thyroid Today, 17:1-9.

British Thyroid Association and Royal College of Physicians. Guidelines for the management of thyroid cancer (2nd ed.). Accessed 9 January 2008. URL: http://www.british-thyroid-association.org/ Thyroid_cancer_guidelines_2007.pdf.

Byar DP, Green SB, Sor P, et al. 1979. A prognostic index for thyroid carcinoma:a study of the E.O.R.T.C. Thyroid Cancer Cooperative Group. Eur J Cancer, 15:1033-41.

Cady B, Sedhwick CE, Meissner WA, et al. 1979. Risk factor analysis in differentiated thyroid cancer. Cancer, 43:810-20.

Carlomagno F, Vitagliano D, Guida T, et al. 2002. ZD6474, an orally available inhibitor of KDR tyrosine kinase activity, efficiently blocks oncogenic RET kinases. Cancer Res, 62:7284-90.

Cheema Y, Repplinger D, Elson D, et al. 2006. Is tumor size the best predictor of outcome for papillary thyroid cancer? Ann Surg Oncol, 13:1524-8.

Chen H, Kunnimalaiyaan M, Van Gompel JJ, et al. 2005. Medullary thyroid cancer:The functions of raf-1 and human achaete-scute homologue-1. Thyroid, 15:511-21.

Chen H, Nicol TL, Udelsman R. 1999. Clinically significant, isolated metastatic disease to the thyroid gland. World J Surg, 23:177-80.

Chen H, Nicol TL, Zeiger MA, et al. 1998b. Hurthle cell neoplasms of the thyroid:Are there factors predictive of malignancy? Ann Surg, 227:542-6.

Chen H, Roberts JR, Ball DW, et al. 1998c. Effective long-term palliation of symptomatic, incurable metastatic medullary thyroid cancer by operative resection. Ann Surg, 227:887-95.

Chen H, Udelsman R. 1998. Papillary thyroid carcinoma: Justification for total thyroidectomy and management of lymph node metastases. Surg Oncol Clin N Am, 7:645-64. 
Chong GC, Beahrs OH, Sizemore GW, et al. 1975. Medullary carcinoma of the thyroid gland. Cancer, 35:695-704.

Clark OH. 1981. TSH suppression of thyroid nodules and thyroid cancer. World J Surg, 5:39-46.

Clark OH. 1982. Total thyroidectomy:The treatment of choice for patients with differentiated thyroid cancer. Ann Surg, 196:361-70.

Clark OH. 1985a. Endocrine surgery of the thyroid and parathyroid glands. St. Louis, MO: The C.V. Mosby Company.

Clark OH, Gerend PL. 1985b. Thyrotropin receptor-adenylate cyclase system in Hurthle cell neoplasms. J Clin Endocrinol Metab, 61:773-8.

Cohen P, Frame S. 2001. The renaissance of GSK3. Nat Rev Mol Cell Bio, 2:769-76.

Colonna M, Grande E, Jónasson JG, et al. 2006. Variation in relative survival of thyroid cancers in Europe: Results from the analysis on 21 countries over the period 1983-1994 (EUROCARE-3 study). Eur J Cancer, 42:2598-608.

Cooper DS, Doherty GM, Haugen BR, et al. 2006. Management guidelines for patients with thyroid nodules and differentiated thyroid cancer Thyroid, 16:109-42.

Dean DS, Hay ID. 2000. Prognostic indicators in differentiated thyroid carcinoma. Cancer Control, 7:229-39.

DeGroot LJ, Kaplan EL, McCortick M, et al. 1990. Natural history, treatment, and course of papillary thyroid cancer. J Clin Endocrinol Metab, 71:414-24.

Duren M, Siperstein AE, Shen W, et al. 1999. Value of stimulated serum thyroglobulin levels for detecting persistent or recurrent differentiated thyroid cancer in high- and low-risk patients. Surgery, 126:13-9.

Emerick GT, Duh QY, Siperstein AE, et al. 1993. Diagnosis, treatment, and outcome of follicular thyroid carcinoma. Cancer, 72:3287-95.

Frazell EL, Foote FW. 1955. Papillary thyroid carcinoma:pathological findsings in cases with and without clinical evidence of cervical node involvement. Cancer, 8:1164-70.

Fogelfeld L, Wiviott MB, Shove-Freedman E, et al. 1989. Recurrence of thyroid nodules after removal in patients irradiated in childhood for benign conditions. $N$ Engl J Med, 320:835-40.

Gimm, O, Ukkat J, Dralle H. 1999. Determinative factors of biochemical cure after primary and reoperative surgery for sporadic medullary thyroid carcinoma. World J Surg, 22:562-7.

Grebe SK, Hay ID. 1996. Thyroid cancer nodal metastases:biologic significance and therapeutic considerations. Surg Oncol Clin N Am, 5:43-63.

Greenblatt DY, Elson D, Mack E, et al. 2007. Initial lymph node dissection increases cure rates in patients with medullary thyroid cancer. Asian J Surg, 30:108-12.

Hanks JB. 2004. Thyroid Malignancies. In Townsend CM, Beauchamp RD, Evers BM, et al. (eds). Sabiston Textbook of Surgery. 17th ed. Philadelphia: Saunders. p. 965-73.

Hardt SE, Sadoshima J. 2002. Glycogen synthase kinase-3 $\beta$ :a novel regulator of cardiac hypertrophy and development. Circ Res, 90:1055-63.

Harwood AJ, Plyte SE, Woodgett J, et al. 1995. Glycogen synthase kinase 3 regulates cell fate in Dictyostelium Cell, 80:139-48.

Haugen BR. 1999. Management of the patient with progressive radio-iodine non-responsive disease. Semin Surg Oncol, 16:34-41.

Hay ID, Bergstralh EJ, Goellner JR, et al. 1993. Predicting outcome in papillary thyroid cancer: development of a reliable prognostic scoring system in a cohort of 1779 patients surgically treated at one institution during 1940 through 1989. Surgery, 114:1050-8.

Hay ID, Grant CS, Bergstralh EJ, et al. 1998. Unilateral total lobectomy: Is it sufficient surgical treatment for patients with AMES low-risk papillary thyroid carcinoma? Surgery, 124:958-66.

Hedinger C, Williams ED, Sobin LH, eds. 1988. Histologic typing of thyroid tumors. In: International Histological Classification of Tumors, No.11. Geneva: World Health Organization; 1-18.

Heijckmann AC, Huijberts MS, Guesens P, et al. 2005. Hip bone mineral density, bone turnover and risk of fracture in patients on long-term suppressive L-thyroxine therapy for differentiated thyroid carcinoma. Eur J Endocrinol, 153:23-9.
Hoelting T, Siperstein AE, Clark OH, et al. 1994. Epidermal growth factor enhances proliferation, migration, and invasion of follicular and papillary thyroid cancer in vitro and in vivo. $J$ Clin Endocrinol Metab, 79:401-8.

Holden SN, Eckhardt SG, Basser R, et al. 2005. Clinical evaluation of ZD6474, an orally active inhibitor of VEGF and EGF receptor signaling, in patients with solid, malignant tumors. Ann Oncol, 16:1391-7.

Hundahl SA, Fleming ID, Fremgen AM, et al. 1998. A National Cancer Data Base report on 53,856 cases of thyroid carcinoma treated in the US, 1985-1995. Cancer, 83:2638-48.

Ito Y, Miyauchi A. 2007. Appropriate treatment for asymptomatic papillary microcarcinoma of the thyroid. Expert Opin Pharmacother, 8:3205-15.

Ito Y, Uruno T, Nakanao K, et al. 2003. An observation trial without surgical treatment in patients with papillary microcarcinoma of the thyroid. Thyroid, 13(4):381-7.

Kadesch T. 2004. Notch signaling: The demise of elegant simplicity. Curr Opin Genet Dev, 14:506-12.

Katoh R, Sasaki J, Kurihara H, et al. 1992. Multiple thyroid involvement (intraglandular metastases) in papillary thyroid carcinoma. A clinicopathologic study of 105 consecutive patients. Cancer, 70:1585-90.

Kebebew E, Clark OH. 2000. Medullary thyroid cancer. Curr Treat Options Oncol, 1:359-67.

Kebebew E, Weng J, Bauer J, et al. 2007. The prevalence and prognostic value of BRAF mutation in thyroid cancer. Ann Surg, 246:466-71.

Kendall-Taylor P, Guidelines Working Group. 2003. Guidelines for the management of thyroid cancer. Clin Endocrinol (Oxf), 58:400-2.

Kim DW, Jo YS, Jung HS, et al. 2006. An orally administered multitarget tyrosine kinase inhibitor, SU11248, is a novel potent inhibitor of thyroid oncogenic RET/papillary thyroid cancer kinases. J Clin Endocrinol Metab, 91:4070-6.

Kim S, Yazici TD, Calzada G, et al. 2007. Sorafenib inhibits the angiogenesis and growth of orthotopic anaplastic thyroid carcinoma xenografts in nude mice. Mol Cancer Ther, 6:1785-92.

Kimura ET, Nikiforova MN, Zhu Z, et al. 2003. High prevalence of BRAF mutations in thyroid cancer:genetic evidence for constitutive activation of the RET/PTC-RAS-BRAF signaling pathway in papillary thyroid carcinoma. Cancer Res, 63:1454-7.

Krishnamurthy GT, Blahd WH. 1977. Radioiodine $\mathrm{I}^{131}$ therapy in the management of thyroid cancer. A prospective study. Cancer, 40:195-202.

Küçük NO, Tari P, Tokmak E, et al. 2007. Treatment for microcarcinoma of the thyroid - clinical experience. Clin Nucl Med, 32:279-81.

Kunnimalaiyaan M, Chen H. 2006. The Raf-1 pathway:a molecular target for treatment of select neuroendocrine tumors? Anticancer Drugs, $17: 139-42$.

Kunnimalaiyaan M, Chen H. 2007. Tumor suppressor role of Notch-1 signaling in neuroendocrine tumors. Oncologist, 12:535-42.

Kunnimalaiyaan M, Haymart M, Chen H. 2007a. Tumor suppressor role of Notch1 and Raf-1 signaling in medullary thyroid cancer cells. Translational Oncogenomics, 2:43-7.

Kunnimalaiyaan M, Vaccaro AM, Ndiaye M, et al. 2006. Overexpression of the NOTCH1 intracellular domain inhibits cell proliferation and alters the neuroendocrine phenotype of medullary thyroid cancer cells. J Biol Chem, 281:39819-30.

Kunnimalaiyaan M, Vaccaro AM, Ndiaye MA, et al. 2007b. Inactivation of glycogen synthase kinase-3 $\beta$, a downstream target of the raf- 1 pathway, is associated with growth suppression in medullary thyroid cancer cells. Mol Cancer Ther, 6:1151-8.

Lam KY, Lo CY, Chan KW, et al. 2000. Insular and anaplastic carcinoma of the thyroid:A 45-year comparative study at a single institution and a review of the significance of $\mathrm{p} 53$ and p21. Ann Surg, 231:329-38.

Lang BH, Lo CY. 2007. Surgical options in undifferentiated thyroid carcinoma. World J Surg, 31:969-77.

Lundgren CI, Hall P, Dickman PW, et al. 2006. Clincally significant prognostic factors for differentiated thyroid carcinoma:a population-based, nested case-control study. Cancer, 106:524-31. 
Machens A, Holzhausen HJ, Dralle H. 2004. Skip metastases in thyroid cancer leaping the central lymph node compartment. Arch Surg, 139:43-5.

Machens A, Hauptmann S, Dralle H. 2007. Increased risk of lymph node metastasis in multifocal hereditary and sporadic medullary thyroid cancer. World J Surg, 31:1960-5.

Maillard I, Pear WS. 2003. Notch and cancer:Best to avoid the ups and downs. Cancer Cell, 3:203-5.

Malaguarnera R, Vella V, Vigneri R, et al. 2007. p53 family proteins in thyroid cancer. Endocr Relat Cancer, 14:43-60.

Manie S, Santoro M, Fusco A, et al. 2001. The RET receptor:function in development and dysfunction in congenital malformation. Trends Genet, 17:580-9.

Mazzaferri E. 1988. Papillary thyroid carcinoma:factors influencing prognosis and current therapy. Semin Oncol, 14:315-32.

Mazzaferri EL. 1999. NCCN thyroid carcinoma practice guidelines. Oncology, 13:391-42.

Mazzaferri EL. 2007. Management of low-risk differentiated thyroid cancer. Endocr Pr, 13:498-512.

Mazzaferri EL, Jhiang SM. 1994. Long-term impact of initial surgical and medical therapy on papillary and follicular thyroid cancer. Am J Med, 97:418-28.

Mazzaferri E, Young RL, Oertel JE, et al. 1977. Papillary thyroid carcinoma: The impact of therapy in 576 patients. Medicine, 56:171-96.

Mazzaferri E, Young RL. 1981. Papillary thyroid carcinoma:A 10 year follow-up report of the impact of therapy in 576 patients. Am J Med, 70:551-558.

Mitsiades CS, Kotoula V, Poulaki V, et al. 2006. Epidermal growth factor receptor as a therapeutic target in human thyroid carcinoma:mutational and functional analysis. J Clin Endocrinol Metab, 91:3662-6.

Moretti F, Farsetti A, Soddu S, et al. 1997. p53 re-expression inhibits proliferation and restores differentiation of human thyroid anaplastic carcinoma cells. Oncogene, 14:729-40.

[NCI] National Cancer Institute Surveillance Epidemiology and End Results Database, US National Institutes of Health. URL: http://seer.cancer. gov/statfacts/html/thyro.html; accessed March 28, 2008.

Olivier M, Eeles R, Hollstein M, et al. 2002. The IARC TP53 database: new online mutation analysis and recommendations to users. Hum Mutat, 19:607-14.

Ozata M, Suzuki S, Miyamoto T, et al. 1994. Serum thyroglobulin in the follow-up of patients with treated differentiated thyroid cancer. J Clin Endocrinol Metab, 79:98-105.

Paloyan E, Walker RP, Lawrence AM. 1998. Guidelines for the use of radioiodine, thyroid hormone, and treatment of metastatic disease in patients with differentiated thyroid cancer. Surg Oncol Clin N Am, 7:665-80

Park JI, Strock CJ, Ball DW, et al. 2003. The ras/raf/MEK/extracellular signal-regulated kinase pathway induces autocrine-paracrine growth inhibition via the leukemia inhibitory factor/JAK/STAT pathway. Mol Cell Biol, 23:543-54.

Perros P, Thyroid Cancer Guidelines Update Group. 2007. Introduction to the updated guidelines on the management of thyroid cancer. Clin Med, 7:321-2.

Pujol P, Daures JP, Nsakala N, et al. Degree of thyrotropin suppression as a prognostic determinant in differentiated thyroid cancer. $J$ Clin Endocrinol Metab, 81:4318-23.

Qubain SW, Nakano S, Baba M, et al. 2002. Distribution of lymph node micrometastases in pN0 well-differentiated thyroid carcinoma. Surgery, 131:249-56.

Ravi RK, Thiagalingam A, Weber E, et al. 1999. Raf-1 causes growth suppression and alteration of neuroendocrine markers in DMS53 human small cell lung cancer cells. Am J Respir Cell Mol Biol, 20:543-9.

Ravi RK, Weber E, McMahon, et al. 1998. Activated raf-1 causes growth arrest in human small cell lung cancers. J Clin Invest, 101:153-9.

Rougier P, Parmentier C, Laplanche A, et al. 1983. Medullary thyroid carcinoma:prognostic factors and treatment. INt J Radiat Oncol Biol Phys, 9:161-169.
Saad MF, Ordonez NG, Rashid RK, et al. 1984. Medullary carcinoma of the thyroid:a study of the clinical features and prognostic factors in 161 patients. Medicine (Baltimore), 63:319-342.

Saltman B, Singh B, Hedvat CV, et al. 2006. Patterns of expression of cell cycle/apoptosis genes along the spectrum of thyroid carcinoma progression. Surgery, 140:899-906.

Salvatore G, De Falco V, Salerno P, et al. 2006. BRAF is a therapeutic target in aggressive thyroid carcinoma. Clin Cancer Res, 12:1623-9.

Sanders LE, Cady B. 1998. Differentiated thyroid cancer:Reexamination of risk groups and outcome of treatment. Arch Surg, 133:419-25.

Sawka AM, Lakra DC, Lea J, et al. 2008a. A systematic review of the gonadal effects of therapeutic radioactive iodine in male thyroid cancer survivors. Clin Endocrinol, 68:610-7.

Sawka AM, Lakra DC, Lea J, et al. 2008b. A systematic review examining the effects of therapeutic radioactive iodine on ovarian function and future pregnancy in female thyroid cancer survivors. Clin Endocrinol, Feb 13 (Epub ahead of print).

Schneider AB, Favus MJ, Stachoura ME, et al. 1978. Incidence, prevalence, and characteristics of radiation-induced thyroid tumors. Am J Med, 64:243-52.

Scollo C, Baudin E, Travalgi JP, et al. 2003. Rationale for central and bilateral lymph node dissection in sporadic and hereditary medullary thyroid cancer. J Clin Endocrinol Metab, 88:2070-5.

Shaha AR. 1998. Management of the neck in thyroid cancer. Otolaryngol Clin North Am, 31:823-31.

Sherman SI. 2003. Thyroid carcinoma. Lancet, 361:501-11.

Shiba E, Miyauchi K, Kobayashi T, et al. 1989. The effect of thyroid hormone on the growth of thyroid cancer [Japanese]. Gan To Kagaku Ryoho, 16:3678-84.

Silverberg SG, Hutter RVP, Foote FW Jr. 1970. Fatal carcinoma of the thyroid: histology, metastases, and causes of death. Cancer, 25:792-802.

Simon D, Goretzki PE, Witte J, et al. 1996. Incidence of regional recurrence guiding radicality in differentiated thyroid carcinoma. World J Surg, 20:860-6.

Sippel RS, Carpenter JE, Kunnimalaiyaan M, et al. 2003. The role of human achaete-scute homolog-1 in medullary thyroid cancer cells. Surgery, 134:866-71

Solans R, Bosch JA, Galofré P, et al. 2001. Salivary and lacrimal gland dysfunction (sicca syndrome) after radioiodine therapy. $J$ Nucl Med, 42:738-43.

Sugino K, Ito K, Mimura T, et al. 2002. The important role of operations in the management of anaplastic carcinoma. Surgery, 131:245-8.

Sywak M, Cornford L, Roach P, et al. 2006. Routine ipsilateral level VI lymphadenopathy reduces postoperative thyroglobulin levels in papillary thyroid cancer. Surgery, 140:1000-7.

Tamura T, Minami H, Yamada Y, et al. 2006. A Phase I dose-escalation study of ZD6474 in Japanese patients with solid, malignant tumors. $J$ Thorac Oncol, 1:1002-9.

Task Force TC. 2001. AACE/AAES medical/surgical guidelines for clinical practice:Management of thyroid carcinoma. Endocr Pr, 7:203-20.

Taylor T, Specker B, Robbins J, et al. 1989. Outcome after treatment of high-risk papillary and non- Hürthle-cell follicular thyroid carcinoma. Ann Int Med, 129:622-7.

Tennvall J, Lundell G, Hallquist A, et al. 1994. Combined doxorubicin, hyperfractionated radiotherapy, and surgery in anaplastic thyroid carcinoma. Cancer, 74:1348-54.

Thyroid Carcinoma Task Force. 2001. AACE/AAES medical/surgical guidelines for clinical practice:management of thyroid carcinoma. American Association of Clinical Endocrinologists. American College of Endocrinology. Endocr Pract, 7:202-20.

Trovisco V, Soares P, Sobrinho-Simoes M. 2006. B-RAF mutations in the etiopathogenesis, diagnosis, and prognosis of thyroid carcinomas. Hum Pathol, 37:781-6.

Udelsman R, Chen H. 1999. The current management of thyroid cancer. Adv Surg, 33:1-27.

Vaccaro A, Chen H, Kunnimalaiyaan M, et al. 2006. In-vivo activation of Raf-1 inhibits tumor growth and development in a xenograft model of human medullary thyroid cancer. Anticancer Drugs, 17:849-53. 
Vidal M, Wells S, Ryan A. 2005. ZD6474 suppresses oncogenic RET isoforms in a Drosphila model for type 2 multiple endocrine neoplasia syndromes and papillary thyroid carcinoma. Cancer Res, 65:3538-41.

Wedge SR, Ogilvie DJ, Dukes M, et al. 2002. ZD6474 inhibits vascular endothelial growth factor signaling, angiongenesis, and tumor growth following oral administration. Cancer Res, 62:4645-55.

Wells S, Gosnell J, Gagel RF, et al. 2007. Vandetanib in metastatic hereditary medullary thyroid cancer:follow-up results of an open-label phase II trial [abstract]. Proc Am Soc Clin Oncol. Abst 6018.

White ML, Gauger PG, Doherty G. 2007. Central lymph node dissection in differentiated thyroid cancer. World J Surg, 31:895-904.

Wong JB, Kaplan MM, Meyer KB, et al. 1990. Ablative radioactive iodine therapy for apparently localized thyroid carcinoma:a decision analytic perspective. Endocrinol Metab Clin North Am, 19:741-60.
Xing M. 2005. BRAF mutation in thyroid cancer. Endocr-Relat Cancer, 12:245-62.

Yeh MW, Rougier JP, Park JW, et al. 2006. Differentiated thyroid cancer cell invasion is regulated through epidermal growth factor receptordependent activation of matrix metalloproteinase (MMP)-2/gelatinase A. Endocr-Relat Cancer, 13:1173-83.

Yoon K, Gaiano N. 2005. Notch signaling in the mammalian central nervous system:Insights from mouse mutants. Nat Neurosci, 8:709-15.

Young RL, Mazzaferri EL, Rahe AJ, et al. 1980. Pure follicular thyroid carcinoma:impact of therapy in 214 patients. J Nuclear Med, 21:733-7.

Yutan E, Clark OH. 2001. Hürthle cell carcinoma. Curr Treat Options Oncol, 2:331-5. 
